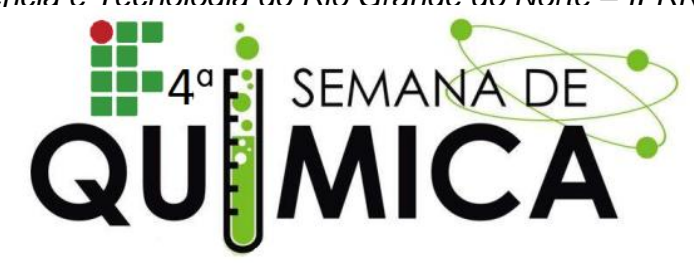

\title{
Estudo do tempo da argila KSF-Dodecilamina na remoção do paracetamol em meio alcoólico e meio aquoso
}

*MORAIS.L.P.S.S. NASCIMENTO.K.K.V. SILVA.M.M.F Instituto Federal De Educação Ciência E Tecnologia Do Rio Grande Do Norte (IFRN-CN)

(*luannapryscila@hotmail.com; katiakarinkarin@gmail.com; marcia.silva@ifrn.edu.br)

Palavras Chave: KSF-Dodecilamina, Adsorção, Paracetamol.

\section{INTRODUÇÃO}

As argilas estão sendo bastante estudadas por serem um material consideravelmete barato e adsorventes alternativos na remoção de efluentes. (ROSSETTO, et al, 2009). Objetivo deste trabalho foi fazer um estudo do tempo entre a argila KSF-Dodecilamina e o paracetamol utilizando os solventes água e álcool com intuito de analisar a maior efetividade de remoção do paracetamol na argila.

\section{METODOLOGIA}

Foi usado o fármaco paracetamol e a argila KSF-Dodecilamina já caracterizada. Realizou-se duas curvas de calibração, uma curva com água e a outra água e álcool. No estudo do tempo, preparou-se duas soluções de 500ppm, uma solução aquosa e outra solução misturando água e álcool para 1L de solução. Foram pesados 12 massas de $0,05 \mathrm{~g}$ da argila modoficada em 12 erlenmayers, feito isso pipetou-se $20 \mathrm{~mL}$ da solução de paracetamol, e adicionou a cada erlenmayers, em seguida colocou as amostras em uma mesa agitadora variando os tempos de 5 a $240 \mathrm{~min}$, a temperatura ambiente. Após os tempos determinados foi centrifugado por $10 \mathrm{~min}$. Retirou as alíquotas de $0,875 \mu \mathrm{L}$ em uma micropipeta e transferiu para um balão $25 \mathrm{~mL}$ e completou com água deionizada, em seguida realizou-se as leituras no UV-Vis na faixa de 243 $\mathrm{nm}$ em absorbância. E a capacidade de adsorção foi calculada pela equação $q=(\mathrm{Ci}-$ Ce)*V/ m. (SILVA, 2011; SILVA, 2012).

\section{RESULTADOS E DISCUSSÕES}

Observou que no estudo do tempo com dois solventes, álcool e água, seus comportamentos na superfície da argila foram praticamente iguais, atingindo o equilíbrio em $15 \mathrm{~min}$. Em solução aquosa a capacidade máxima de adsorção foi de 192,32 mg/g e para solução em meio alcoólico foi de $192,73 \mathrm{mg} / \mathrm{g}$. Contudo percebeu-se que não ocorreu mudanças significativas na adsorção do fármaco com a variação dos solventes.

\section{CONCLUSÃO}

Conforme os resultados apresentados da máxima retenção do paracetamol na argila KSFDodecilamina confirmaram-se o sucesso do processo de adsorção. Mostrando um excelente adsorvente na remoção do fármaco do meio ambiente.

\section{REFERÊNCIAS}

1.ROSSETTO, Enéderson. et al. Caracterização de Bentonitas Sódicas: Efeito do Tratamento com Surfactante Orgânico Livre de Sal de Amônio. Quimica nova, Erechim - RS, Brasil, v. 32, n. 8, p. 1-4. 2009.

2.SILVA, MÁRCIA.M.F. Híbridos da montmorillonita-KSF contendo grupos alquilamina - Síntese, caracterização e aplicações adsortivas.p.142. Tese Doutorado Universidade Federal da Paraíba. Centro de Ciência Exatas e da Natureza. Departamento de Química, Novembro de 2011.

3.SILVA, Márcia M.F. et al. Adsorption of an industrial anionic dye by modified-KSF-montmorillonite: Evaluation of the kinetic, thermodynamic and equilibrium data. Chemical Engineering Journal. TerezinaPI-Brasil. p.259 a 268. 11/07/2012. 